\title{
Prediction of individual immune responsiveness to a candidate vaccine by a systems vaccinology approach
}

\author{
Annacarmen Petrizzo, Maria Tagliamonte, Maria Lina Tornesello, Franco M Buonaguro and Luigi Buonaguro*
}

\begin{abstract}
Background: We have previously shown that a candidate idiotype vaccine, based on the IGKV3-20 light chain protein, is able to induce activation of circulating antigen presenting cells (APCs) in both HCV-positive and HCV-negative subjects, with production of Th2-type cytokines. In addition, such a candidate idiotype vaccine induces an early gene expression pattern, characterized by the strong induction of an innate immune response, and a late pattern, characterized by a prevalent B cell response. Nonetheless, some HCV-positive individuals showed a complete lack of maturation of circulating APCs with low levels of cytokine production, strongly suggesting the possible identification of selective impairments in immune response in individual subjects.

Method: Peripheral blood mononuclear cells (PBMCs) were stimulated ex vivo with IGKV3-20 for $24 \mathrm{~h}$ and 6 days. Analysis of the global gene expression profile as well as the cytokine pattern was performed for individual subjects.

Results: The gene expression profile showed a strong agreement with the cytokine pattern. Indeed, the expression pattern of immune-related genes is highly predictive of the individual immunological phenotype.

Conclusion: The overall results represent a proof of concept, indicating the efficacy of such an ex vivo screening platform for predicting individual's responsiveness to an antigen as well as guiding optimization of vaccine design. Larger cohort study will be needed to validate results observed in the study.
\end{abstract}

Keywords: Hepatitis C Virus, Non-Hodgkin's Lymphoma, Idiotype vaccine, Immune response, Systems biology

\section{Introduction}

Hepatitis $\mathrm{C}$ virus (HCV) is a Hepacivirus of the Flaviviridae family, mainly involved in hepatic disorders, including chronic hepatitis, cirrhosis and hepatocellular carcinoma (HCC) [1].

$\mathrm{HCV}$ has also been recognized as the major etiologic factor of type II mixed cryoglobulinemia (MC), an autoimmune disease ultimately leading to B cell non-Hodgkin's lymphoma (NHL) in about $10 \%$ of MC patients [2-5].

The clonal $\mathrm{B}$ cell expansion is characterized by the production of an Ig molecule expressing a unique combination of antigen-specific sequences, the so called idiotype (Id). Therefore, the Id can be a suitable target for

\footnotetext{
* Correspondence: l.buonaguro@istitutotumori.na.it

Laboratory of Molecular Biology and Viral Oncology, Department of

Experimental Oncology, Istituto Nazionale per lo Studio e la Cura dei Tumori,

"Fondazione Pascale" - IRCCS, Naples, Italy
}

active, as well as passive immune-therapeutic strategies to eliminate the B cells driving the tumor $[6,7]$.

In this respect, the IGKV3-20 idiotype has been selected as a potential target of either passive immune therapy or active vaccine strategy [8].

We have previously reported the results of the effect of the IGKV3-20 candidate idiotype vaccine on ex vivo stimulated PBMCs, as experimental platform for evaluation and prediction of responsiveness to vaccination [9]. IGKV3-20 light chain protein has been shown to induce activation of circulating APCs, i.e., $\mathrm{CD} 14^{+}$monocytes, as well as $\mathrm{CD}_{123^{+}}$plasmacytoid dendritic cells (pDCs) and $\mathrm{CD}_{11 \mathrm{c}^{+}}$myeloid DCs (mDCs), in both $\mathrm{HCV}$-positive and $\mathrm{HCV}$-negative healthy control subjects, with production of Th2-type cytokines $[9,10]$. No significant difference was observed between results obtained in human monocyte-derived dendritic cells 
(MDDCs) and circulating APCs, confirming previous results by us and other groups [11-15].

Moreover, such a candidate idiotype vaccine induces an early expression pattern, characterized by the induction of genes related to inflammatory response, and a late pattern, characterized by the induction of genes related to a B cell response [10].

Indeed, the Ingenuity Pathways Analysis (IPA) performed on "early" and "late" up-regulated genes showed a prevalence of inflammation and innate immunity-related pathways activated at $24 \mathrm{~h}$ post-induction, with significant overlapping between $\mathrm{HCV}$-negative and positive groups, and a prevalence of "atypical" immune pathways activated at 6 days post-induction [10].

Nonetheless, some HCV-positive and negative subjects showed a poor response to the IGKV3-20 protein, with significant low levels of cytokine production and limited gene expression pattern.

In this regard, here we describe a systems biology approach to evaluate the individual responsiveness to the recombinant IGKV3-20 protein, aiming at identifying a possible impairment in the immune response and/or markers of responsiveness to such a specific antigen. Indeed, the specific effect of the recombinant IGKV3-20 protein has been evaluated ex vivo on human PBMCs of individual $\mathrm{HCV}$-positive subjects via multiparametric analyses, including gene expression profiling combined to multiplex analysis of cytokines.

\section{Materials and methods}

\section{Clinical specimens and cell treatment}

Overall, samples from six HCV-positive subjects were analysed for the present study. Samples from five healthy donors were used as controls. Enrollment of subjects and treatment of derived human PBMCs have been previously described [10].

\section{Unsupervised analysis}

For the unsupervised analysis a low-stringency filtering was applied, selecting the genes differentially expressed in $80 \%$ of all experiments with a $>3$ fold change ratio in at least one experiment. Hierarchical cluster analysis was conducted on the selected genes according to Eisen et al. [16]; differentially expressed genes were visualized by Treeview and displayed according to the central method [16,17].

\section{Supervised analysis}

Supervised class comparison was performed using BRB ArrayTool developed at NCI, Biometric Research Branch, Division of Cancer Treatment and Diagnosis. Two subsets of genes were explored. The first subset included genes up-regulated in stimulated (IGKV3-20 treated) PBMCs compared to non-stimulated (PBS treated) PBMCs after
$24 \mathrm{~h}$ incubation; the second subset included genes upregulated in stimulated PBMCs compared to nonstimulated PBMCs after 6 days incubation.

Class comparison analyses were tested for an univariate significance threshold set at a $p$-value $<0.001$. Gene clusters identified by the univariate $t$-test were challenged with two alternative additional tests, an univariate permutation test (PT) and a global multivariate PT.

Class comparison and hierarchical clustering were employed to determine the pattern of response and results are illustrated as a heat map of significance values. All analyses were performed using $\mathrm{R}$ and Cytoscape (http://www. cytoscape.org). Gene function was assigned based on Database for Annotation, Visualization and Integrated Discovery (DAVID) (http://david.abcc.ncifcrf.gov) and Gene Ontology (http://www.geneontology.org).

Ingenuity Pathways Analysis (IPA, www.ingenuity.com) was employed to elucidate the relationship and connection between differentially expressed genes.

\section{Results}

\section{Cytokine pattern induced in circulating APCs}

PBMCs obtained from enrolled subjects were incubated with IGKV3-20 for $24 \mathrm{~h}$ and 6 days and, at each timepoint, levels of Th1 (IL-2 and TNF- $\alpha$ ) and Th2 (IL-5, IL6 and IL-10) cytokines were assessed by ELISA in the culture supernatant. The results show that the stimulation induces a significant production of both Th1 (TNF$\alpha)$ and Th2 cytokines (IL-6 and IL-10) with a prevalent Th2-biased cytokine pattern, as previously reported [10].

However, specific subjects show levels of cytokine induction significantly far from the mean value, indicating that differences may be observed in the response elicited by the antigen (Figure 1).

Indeed, at $24 \mathrm{~h}$ post-induction, PBMCs of subject DN always score at the top for release of TNF- $\alpha$, IL- 6 and IL-10 (1.7, 1.2 and 2.1 folds over the average, respectively). PBMCs of subject BE show a very similar pattern for TNF- $\alpha$ and IL-6 (1.8 and 1.2 folds over the average, respectively), whereas the amount of IL-10 released is the lowest ( 0.2 folds over the average). On the contrary, PBMCs of subjects MML and BD release the lowest levels of TNF- $\alpha$ and IL-6 (0.4 and 0.8 folds over the average, respectively) (Figure 1A).

Overall, high levels of IL- 6 persist for the 6 days of induction, whereas the induction of IL-10 and, even more, TNF- $\alpha$ fades away at 6 days (Figure 1B).

Nevertheless, only PBMCs of subject BE (unlike those of $\mathrm{DN}$ ) are confirmed to release the highest amount of TNF- $\alpha$ and IL- 6 , while PBMCs of subject VA release the highest amount of IL-10 (Figure 1B). As for the $24 \mathrm{~h}$ time-point, PBMCs of MML are confirmed to release the lowest amount of all three cytokines (Figure 1B). The overall results, therefore, indicate distinct cytokine 


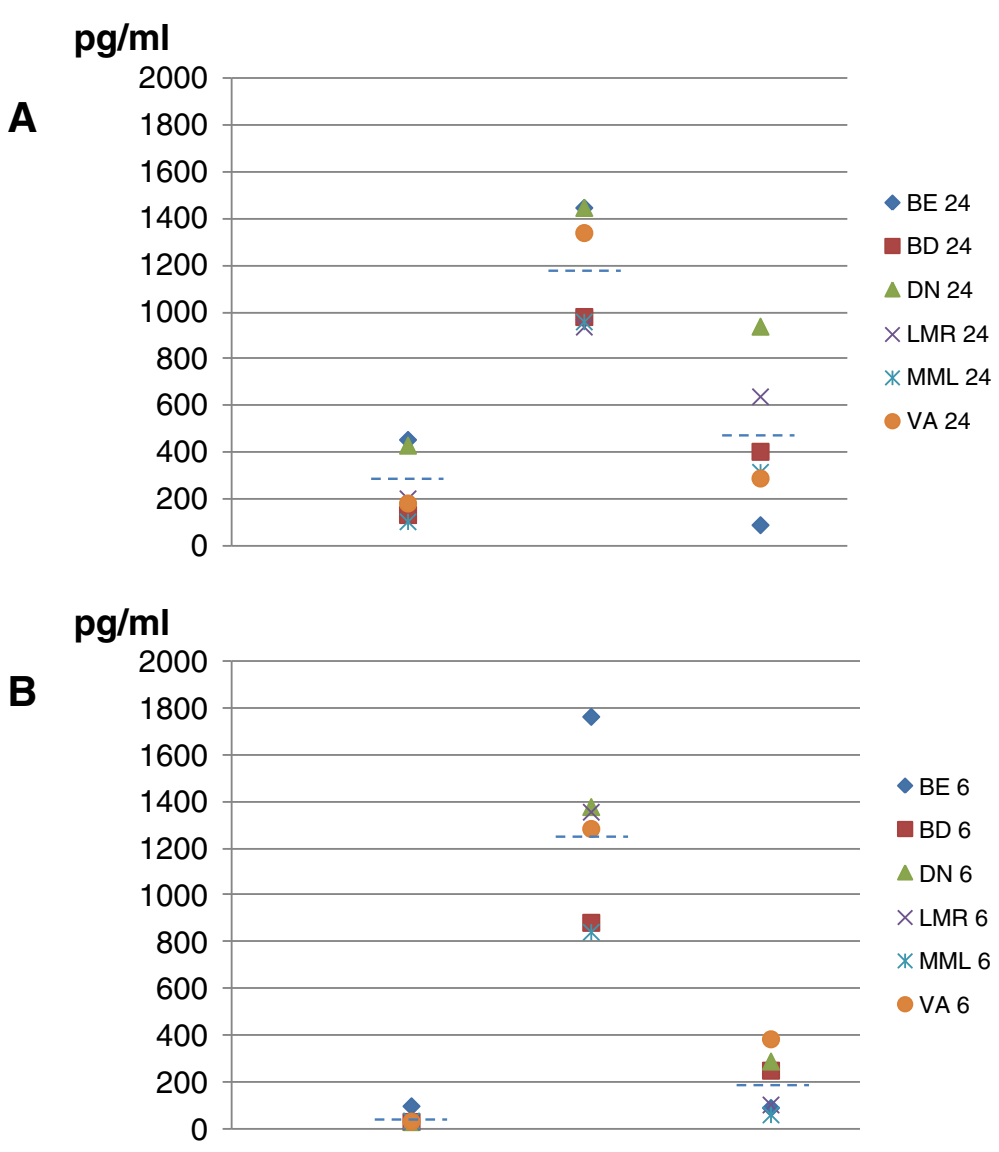

Figure 1 Analysis of cytokine production in supernatant of PBMCs. The cytokine profile induced by IGKV3-20 after $24 \mathrm{~h}$ (A) and 6d (B) incubation was evaluated in supernatant of stimulated PBMCs.

patterns elicited by the same antigen ex vivo which may possibly reflect differences in individual response to the same antigen after in vivo vaccination.

\section{Identification of immune response pattern to IGKV3-20 at "early" time-point}

Subsequently, the gene expression profile of samples from HCV-positive subjects, previously analyzed as whole group [10], was evaluated to identify individual patterns induced by recombinant IGKV3-20 on PBMCs from six HCV-positive subjects. To this aim, a supervised pair-wise comparison was performed between stimulated (IGKV320 treated) and non-stimulated (PBS) PBMCs.

The analysis at $24 \mathrm{~h}$ identified a clustering confirming the different response of samples BE (high) and MML (low) observed in the pattern of cytokine production induced by IGKV3-20 stimulation.

In particular, 394 genes differentially expressed were overall identified (201 up-regulated genes and 193 downregulated genes) with the strongest gene activation induced in PBMCs of subject BE and the weakest one induced in PBMCs of subject MML (Figure 2). The remaining 4 samples showed an intermediate transcriptional pattern, suggesting the possible identification of high vs. weak responders according to results of simultaneous gene expression data. A list of modulated genes correlated with immunology functions is shown in Table 1.

The identified genes were further evaluated, to identify specific transcription profiles in the individual subjects. Considering the immune-related genes, heat maps in Figures $2 \mathrm{~A}$ and $\mathrm{B}$ show a very strong up-regulation of specific genes mostly in sample BE (e.g., G0S2, VNN3, CCL18, TNFAIP6, IL-1A, CD80, TRAF1 and SNX9). An additional set of cytokine and cytokine receptor related genes, instead, shows a broad activation in all samples including BE (e.g., IL-1B, IL-6, IL-24, CCL23, CCL20 and IL2RA). The only exception is represented by the subject MML which shows a very limited pattern of gene activation and even down-regulation (Figure 2A and B).

Among the genes more strongly activated in $\mathrm{BE}$, the TNF alpha-induced protein 6 (TNFAIP6), TNF receptorassociated factor 1 (TRAF1), G0/G1 switch gene 2 (G0S2), vanin-3 (VNN3) and sorting nexin 9 (SNX9) possibly suggest the activation of a TNF-mediated inflammatory pattern induced by IGKV3-20. Indeed, both TNFAIP6 and TRAF1 are downstream mediators of TNF signaling [18] 


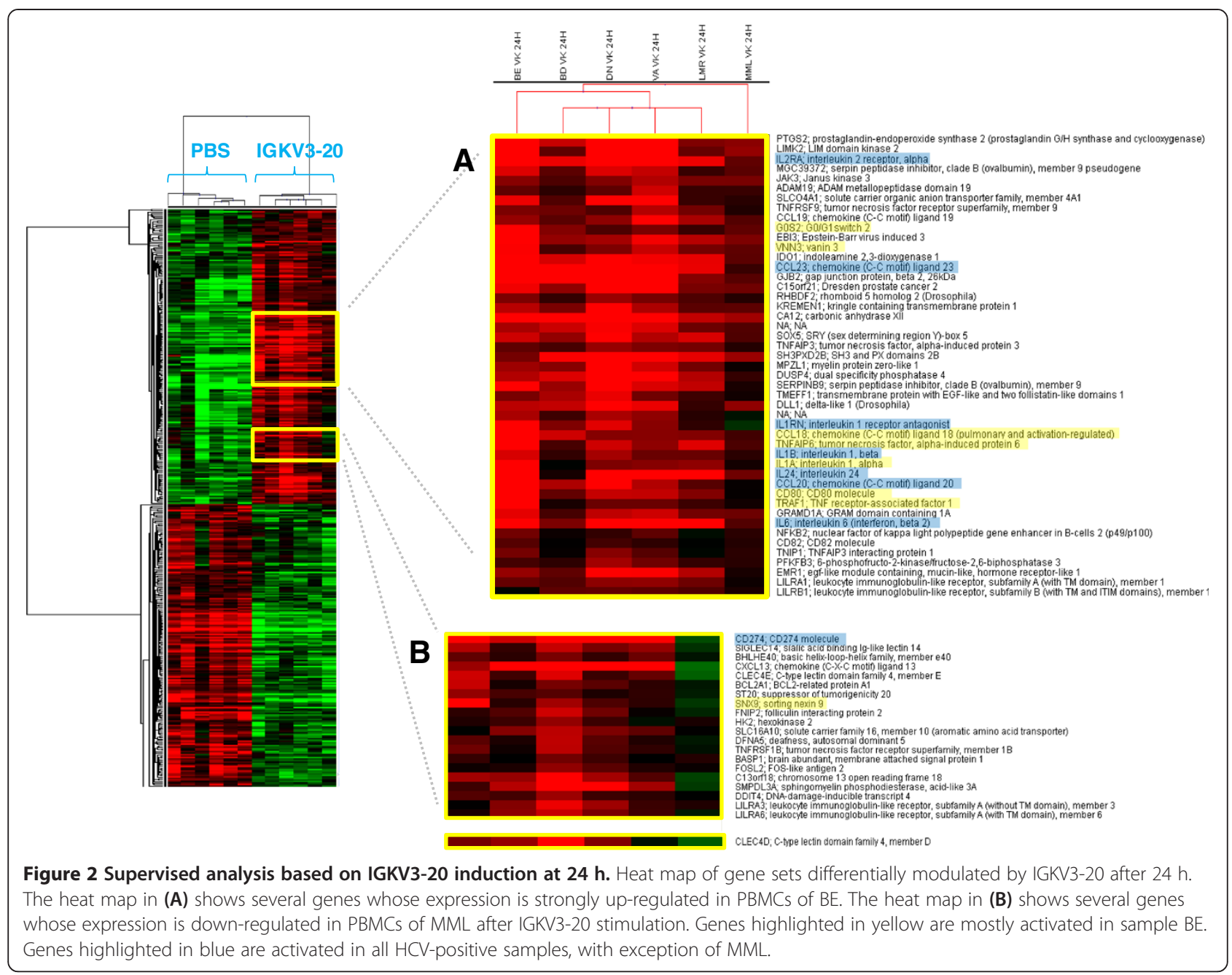

[19], whereas G0S2 is known to be induced by TNF through the activation of the NFKB complex [20]. Moreover, SNX9 promotes internalization of TNFR [21], whereas VNN3 induction is mediated by Th17/Th1 type cytokines, including TNF- $\alpha$ [22].

Indeed, the pronounced pro-inflammatory pattern induced by IGKV3-20 in PBMCs of BE is more similar to the expression profile elicited in samples from healthy control subjects (Figure 3).

Furthermore, the strong up-regulation of CCL18 and CD80 molecules confirms the significant activation of circulating APCs by IGKV3-20 (Figures 2A and 3) [10].

On the other hand, PBMCs of subject MML show downregulation of tumor necrosis factor receptor superfamily member 1B (TNFRSF1B), a mediator of most of the metabolic effects of TNF- $\alpha$, as well as of interleukin 1 receptor antagonist (IL1RN), whose expression is implicated in the modulation of the inflammasome (Figure 2A and B) [23]. This observation suggests the limited pro-inflammatory effect of TNF- $\alpha$ and IL-1 induced by IGKV3-20 in PBMCs of MML.
Furthermore, C-type lectin domain family 4 member D (CLEC4D), involved in antigen uptake for processing and further presentation to $\mathrm{T}$ cells, is strongly down-regulated in PBMCs of MML upon treatment with IGKV3-20, suggesting a possible impairment of the antigen uptake, processing and presentation pathway [24,25].

Unexpectedly, CD274 molecule, which has been speculated to play a major role in suppressing the immune system during autoimmune disease and disease states, including hepatitis, is down-regulated by IGKV3-20 in PBMCs of MML while strongly up-regulated in all the other HCV-positive samples (Figure 2B) [26].

\section{Identification of immune response pattern to IGKV3-20 at "late" time-point}

To evaluate a change in the gene expression pattern over-time, the transcriptional profiling analysis was performed also after 6 days ("late") incubation (Figure 4).

The comparison analysis at this late time-point confirmed the different clustering of samples BE and MML. Overall, 105 genes differentially expressed were identified, 
Table 1 Immunology genes modulated by IGKV3-20 at 24 h

\begin{tabular}{|c|c|c|c|c|c|}
\hline Gene ID & Gene symbol & Gene name & Gene ID & Gene symbol & Gene name \\
\hline 7960947 & A2M & Alpha-2-macroglobulin & 8154733 & ACO1 & Aconitase 1, soluble \\
\hline 8093294 & CCR2 & Chemokine receptor 2 & 8071899 & ADORA2A & Adenosine A2a receptor \\
\hline 7937508 & CD151 & CD151 molecule & 7990818 & $\mathrm{BCL} 2 \mathrm{~A} 1$ & $\mathrm{BCL} 2$-related protein $\mathrm{A} 1$ \\
\hline 8133876 & CD36 & CD36 molecule & 8089771 & CD80 & CD80 molecule \\
\hline 7953428 & CD4 & CD4 molecule & 7898655 & CDA & Cytidine deaminase \\
\hline 8115147 & CD74 & MHC, class II invariant chain & 8042942 & HK2 & Hexokinase 2 \\
\hline 8082035 & CD86 & CD86 molecule & 8025601 & ICAM1 & Intercellular adhesion mol. 1 \\
\hline 7966089 & CMKLR1 & Chemokine-like receptor 1 & 8097553 & IL15 & Interleukin 15 \\
\hline 8115076 & CSF1R & Colonystimul. factor 1 recep. & 8054712 & IL $1 \mathrm{~A}$ & Interleukin 1, alpha \\
\hline 8065403 & CST3 & Cystatin C & 8054722 & IL1B & Interleukin 1 , beta \\
\hline 8166730 & CYBB & Cytochrome b-245, beta polypeptide & 8044574 & IL1RN & Interleukin 1 receptor antagonist \\
\hline 8108370 & EGR1 & Early growth response 1 & 7931914 & IL2RA & Interleukin 2 receptor, alpha \\
\hline 7985268 & $\mathrm{FAH}$ & Fumarylacetoacetate hydrolase & 8131803 & IL6 & Interleukin 6 \\
\hline 816502 & FBP1 & Fructose-1,6-bisphosphatase 1 & 8077786 & IRAK2 & IL1 receptor-ass. kinase 2 \\
\hline 8165011 & FCN1 & Ficolin 1 & 8035351 & JAK3 & Janus kinase 3 \\
\hline 8058765 & FN1 & Fibronectin 1 & 7973336 & MMP14 & Matrix metallpeptidase 14 \\
\hline 7913694 & FUCA1 & Fucosidase, alpha-L-1, tissue & 7951217 & MMP7 & Matrix metallopeptidase 7 \\
\hline 8129974 & FUCA2 & Fucosidase, alpha-L-2, plasma & 8172220 & NDP & Norrie disease \\
\hline 8163908 & GGTA1 & $\begin{array}{l}\text { Glycoprotein, alpha- } \\
\text { galactosyltransferase } 1 \text { pseudogene }\end{array}$ & 7930074 & NFKB2 & $\begin{array}{l}\text { Nuclear factor of kappa light polypeptide gene enhancer } \\
\text { in B-cells } 2 \text { (p49/p100) }\end{array}$ \\
\hline 8180346 & GPX1 & Glutathione peroxidase 1 & 8075316 & OSM & Oncostatin M \\
\hline 8157582 & GSN & Gelsonlin & 8062927 & $\mathrm{Pl} 3$ & Peptidase inhibitor 3 \\
\hline 7941936 & GSTP1 & Glutathione S-transferase pi 1 & 8150509 & PLAT & Plasmin. activator, tissue \\
\hline 8140556 & HGF & Hepatocyte growth factor & 8037775 & PTGIR & Prostagladin 12 receptor (IP) \\
\hline 8180086 & HLA-DMA & MHC, class II, DM alpha & 7922976 & PTGS2 & Prostag-endoperox synthase 2 \\
\hline 8180078 & HLA-DMB & MHC, class II, DM beta & 7977786 & SLC7A7 & Solute carrier fam 7, memb 7 \\
\hline 8180100 & HLA-DPA1 & MHC, class II, DP alpha 1 & 8130556 & SOD2 & Superoxide dismutase 2 \\
\hline 8179519 & HLA-DPB1 & MHC, class II, DP beta 1 & 8066214 & TGM2 & Transglutaminase 2 \\
\hline 8179481 & HLA-DRA & MHC, class II, DR alpha & 8045688 & TNFAIP6 & TNF, alpha-induced protein 6 \\
\hline 8058552 & $\mathrm{IDH} 1$ & Isocitrate dehydrognase 1 & 7897877 & TNFRSF1B & TNF receptor superfam, 1B \\
\hline 7942300 & IL18BP & Interleukin 18 binding protein & 7912145 & TNFRSF9 & TNF rec. superfam, memb 9 \\
\hline 8070826 & ITGB2 & Intergrin, beta 2 & 8163825 & TRAF1 & TNF receptor-assoc. factor 1 \\
\hline 8090162 & ITGB5 & Integrin, beta 5 & & & \\
\hline 7957023 & $L Y Z$ & Lysozyme & & & \\
\hline 8127854 & ME1 & Malic enzyme 1 & & & \\
\hline 7926451 & $\mathrm{MRC1}$ & Mannose receptor, C type 1 & & & \\
\hline 8149448 & MSR1 & Macrophage scavenger recept 1 & & & \\
\hline 8076403 & NAGA & $\mathrm{N}$-acetylgalactosaminidase, a & & & \\
\hline 8072744 & NCF4 & Neutrophil cytosolic factor 4 & & & \\
\hline 8157650 & PTGS1 & Prostag-endoperoxsynthase 1 & & & \\
\hline 7920271 & S100A4 & S100 calcium binding protein A4 & & & \\
\hline 8136557 & TBXAS1 & Thromboxane A synthase 1 & & & \\
\hline 8157524 & TLR4 & Toll-like receptor 4 & & & \\
\hline 7924499 & TLR5 & Toll-like receptor 5 & & & \\
\hline
\end{tabular}

Down-regulated (left) and up-regulated (right) genes. 
of which 82 up-regulated and 23 down-regulated upon IGKV3-20 stimulation. A list of modulated genes correlated with immunology functions is shown in Table 2. The number of differentially expressed genes at late time-point is drastically reduced compared to the early time-point, but it is still indicative of a late modulation of the immune response by IGKV3-20.

Among the up-regulated genes CD300E, CLEC4D and FCAR are mostly activated in sample BE (Figure 4B). Moreover, several members of the leukocyte immunoglobulinlike receptor (LILR) family (i.e., LILRA1, LILRA3 and LILRA5) are activated, indicating a relevant role for such innate immune receptors, expressed on monocytes and $\mathrm{B}$ cells, in the response elicited by the IGKV3-20 (Figure 4A and $B)[27]$.

Even at 6 days the expression pattern induced by IGKV3-20 in PBMCs of BE strongly resembles the expression profile elicited by the same antigen in a cohort of healthy control subjects, as indicated by the dendrogram at the top of matrix in Figure 5.

On the other hand, immune genes such as LILRA3, CXCL13, CRLF2 and CD82 are even down-regulated in sample MML, suggesting the inefficient delivery of costimulatory signals for the $\mathrm{T}$ cell receptor (TCR)/CD3 pathway for such a subject (Figure 4A) [28].

\section{Identification of unique immune signatures in PBMCs of BE and MML}

A subsequent supervised analysis was performed individually comparing sample BE or MML to all the other samples, and such analysis included all genes modulated by IGKV3-20 without subtracting the basal expression patterns (i.e., PBS).

In regards to PBMCs of subject BE, overall 102 differentially expressed genes were identified at $24 \mathrm{~h}$ post stimulation, of which 62 up-regulated and 40 downregulated genes (data not shown).

Among the up-regulated genes, several were identified as immunology genes and the resulting immunology network was visualized using Cytoscape (http://www.cytoscape.org) (Figure 6A).

At 6 days post stimulation, overall 617 differentially expressed genes were identified, of which 349 upregulated and 268 down-regulated genes (data not shown). Interestingly, a unique gene signature was identified, characterized by the up-regulation of Th1 cytokine (i.e., TNF and IFN $\gamma$ ) and cytokine receptor (i.e., IL2RB, IL18R1 and IL12RB2) genes, as well as high-affinity Fc-gamma receptor genes (i.e., FCGR1A and FCGR1B) (Figure 6B). All these genes contribute to the inflammatory response, promoting proliferation of natural killer (NK) cells, as well as T-cells of the Th1 phenotype, strongly suggesting a loop of specific activation of the IFN $\gamma$ signaling [29], confirmed also by the IPA analysis (Figure 7).

On the other hand, in PBMCs of subject MML, the analysis identified overall 479 differentially expressed genes at $24 \mathrm{~h}$, whereas 122 genes were differentially expressed at 6 days (data not shown). However, marker genes of the immune response were not identified up-regulated and most of the identified genes were not even annotated.

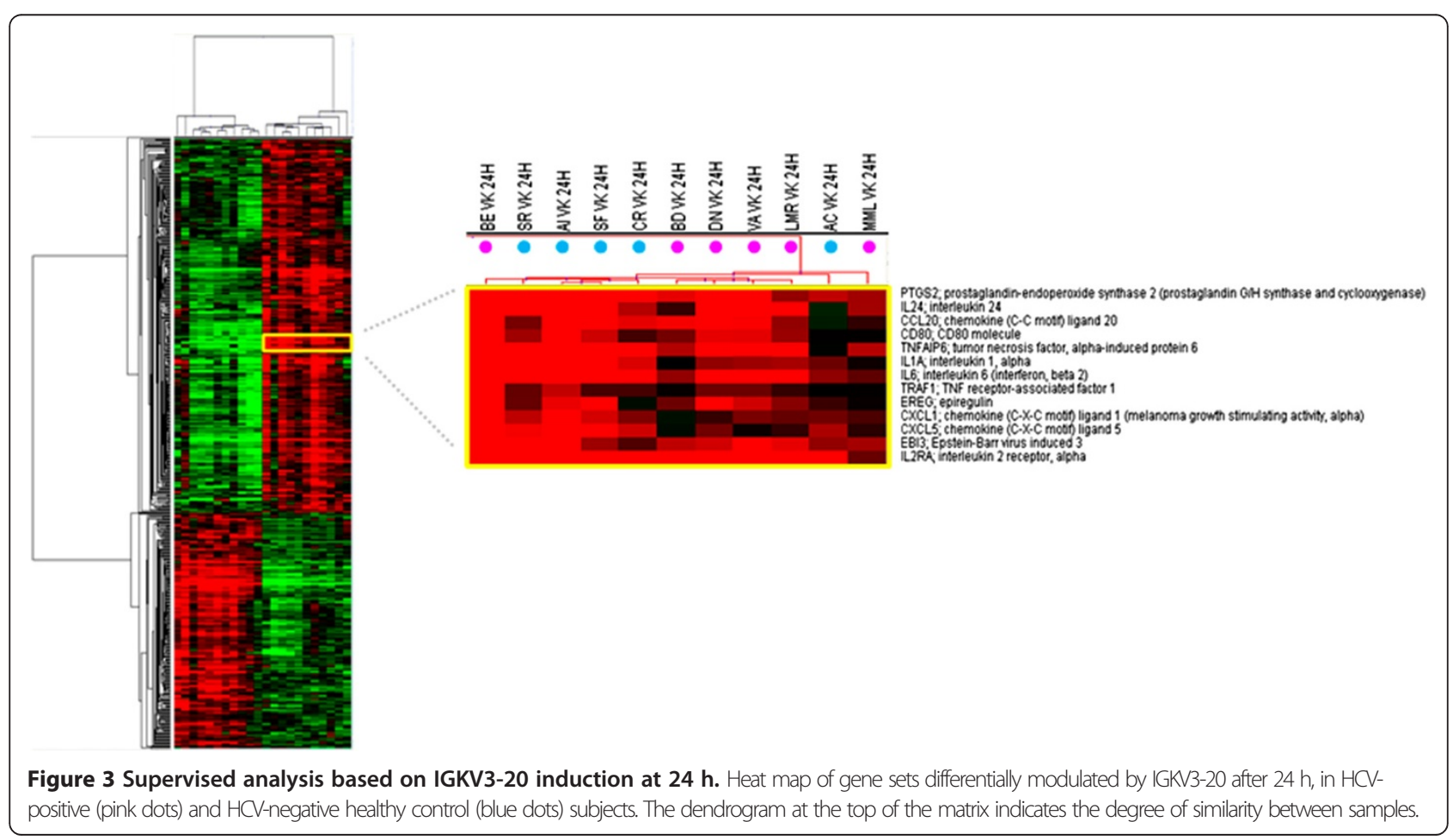




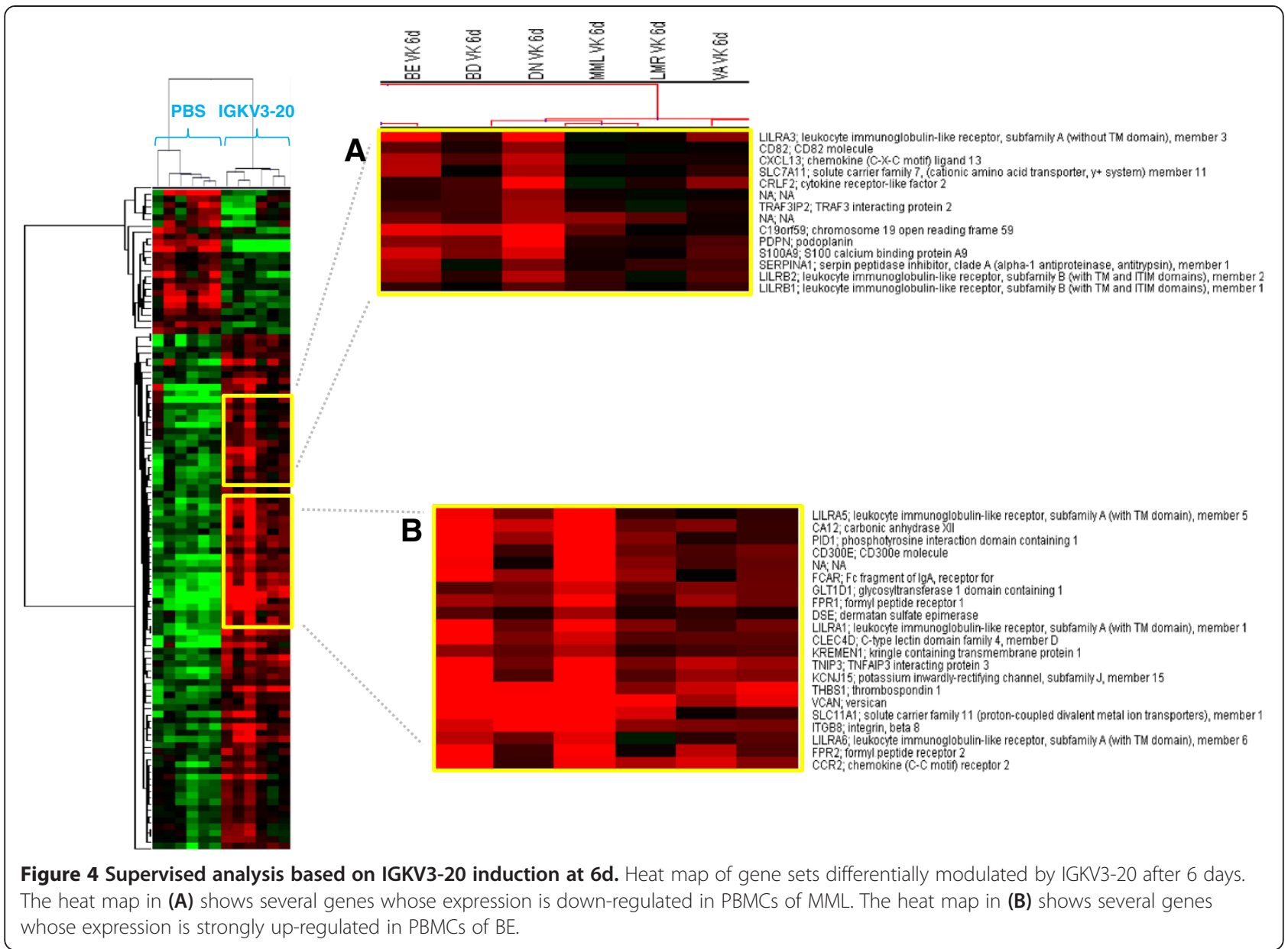

Interestingly, several immunology and killer-cell-receptor genes (i.e., KLRD1, KLRB1, KLRF1, KIR2DL4, KIR2DS1) were found down-regulated (Figure 6C and D), suggesting a possible impairment of the NK cell function in such a subject [30].
The overall results suggest the identification of molecular markers of individual response to a specific antigen, which could represent a platform for the identification of common predictive signatures of response to vaccination.

Table 2 Immunology genes modulated by IGKV3-20 at 6 days

\begin{tabular}{|c|c|c|c|c|c|}
\hline Gene ID & Gene symbol & Gene name & Gene ID & Gene symbol & Gene name \\
\hline 7960947 & $\mathrm{~A} 2 \mathrm{M}$ & Alpha-2-macroglobulin & 8093294 & CCR2 & Chemokine receptor 2 \\
\hline 8127854 & ME1 & Malic enzyme 1, NADP(+)-dependent, cytosolic & 8063386 & CEBPB & CCAAT/enhancer binding protein (C/EBP), beta \\
\hline \multirow[t]{8}{*}{7948444} & \multirow[t]{8}{*}{ TCN1 } & \multirow[t]{8}{*}{ Transcobalamin I } & 8031374 & FCAR & Fc fragment of IgA, receptor for \\
\hline & & & \multirow{2}{*}{7921873} & \multirow{2}{*}{ FCGR3A } & Fc fragment of IgG, low affinity \\
\hline & & & & & Illa, receptor (CD16a) \\
\hline & & & 8038899 & FPR1 & Formly peptide receptor 1 \\
\hline & & & 8042942 & HK2 & Hexokinase 2 \\
\hline & & & 8047086 & NAB1 & NGFI-A binding protein 1 (EGR1 binding protein 1) \\
\hline & & & 7920244 & S100A8 & S100 calcium binding protein A8 \\
\hline & & & 7982597 & THBS1 & Thrombospodin 1 \\
\hline
\end{tabular}




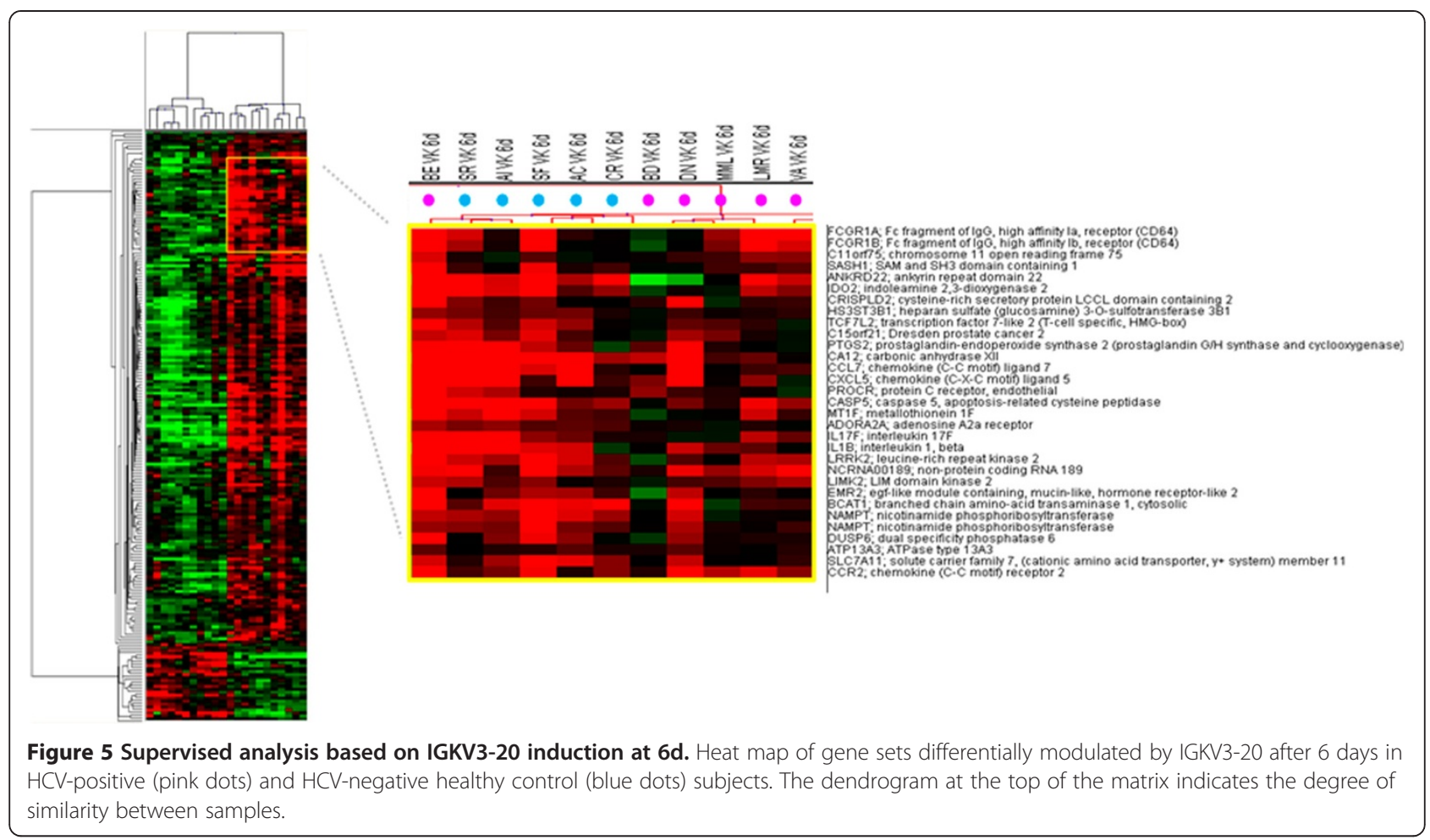

\section{Discussion}

A major challenge in vaccinology is to predict vaccine efficacy [31-33]. Here, we used a multiparametric systems biology approach to identify gene signatures predictive of an immune response, using an experimental platform based on PBMCs from $6 \mathrm{HCV}$-positive subjects stimulated ex vivo with the IGKV3-20 light-chain protein, as candidate idiotype vaccine.

The cytokine pattern induced by IGKV3-20 was assessed by ELISA in culture supernatant of stimulated PBMCs, after $24 \mathrm{~h}$ or 6 days of incubation (Figure 1).

The results show that the stimulation induces an overall significant production of both Th1 (TNF- $\alpha$ ) and Th2 cytokines (IL-6 and IL-10), with a prevalence of the latters. However, specific samples consistently show very different levels of TNF- $\alpha$ and IL- 6 production, which are highest for samples $\mathrm{BE}$ and $\mathrm{DN}$ and lowest for sample MML. These results, although based on a small cohort, indicate a significant difference in the individual response to the same antigen and, in particular, suggest that subject $\mathrm{BE}$ is characterized by a relevant pro-inflammatory pattern with the highest levels of IL- 6 and TNF- $\alpha$ and the lowest level of the antiinflammatory IL-10 (Figure 1).

The global gene expression profile of PBMCs stimulated with IGKV3-20 for $24 \mathrm{~h}$ and 6 days confirmed such strong differences between BE and MML.

Indeed, in agreement with the cytokine expression pattern, the sample from subject $B E$ shows the highest number of strongly activated genes, whereas the sample from subject MML shows the weakest transcriptional profile (Figures 2 and 4).

In particular, considering immune-related genes upregulated at $24 \mathrm{~h}$, the activation of a TNF-mediated inflammatory pattern in subject BE induced by IGKV3-20 is strongly suggested (Figure 2A). Moreover, the upregulation of CCL18 and CD80 molecules suggests a significant activation of circulating APCs in this subject (Figure 2A). On the contrary, several immune-related genes are even down-regulated in PBMCs of MML, suggesting a possible impaired activation of a pro-inflammatory and/or immune response by the antigen.

The strong difference in transcriptional profile of immune-related genes between subjects BE and MML is confirmed also after 6 days of incubation with IGKV3-20 (Figure 4).

Indeed, $\mathrm{BE}$ shows the gene activation of several members of the LILR (i.e., LILRA1, LILRA3 and LILRA5) family of immunoreceptors, as well as CD300E, CLEC4D and FCAR (Figure 4A and B).

More importantly, the supervised analysis performed on the pool of genes modulated by IGKV3-20, without subtracting PBS pattern, identified a late transcriptional profile characterized by the up-regulation of TNF, IFN $\gamma$, IL2RB, IL18R1, IL12RB2, FCGR1A and FCGR1B genes (Figure 6B), which is unique for subject $B E$ and suggestive of a possible Th1-polarization of the immune response. 

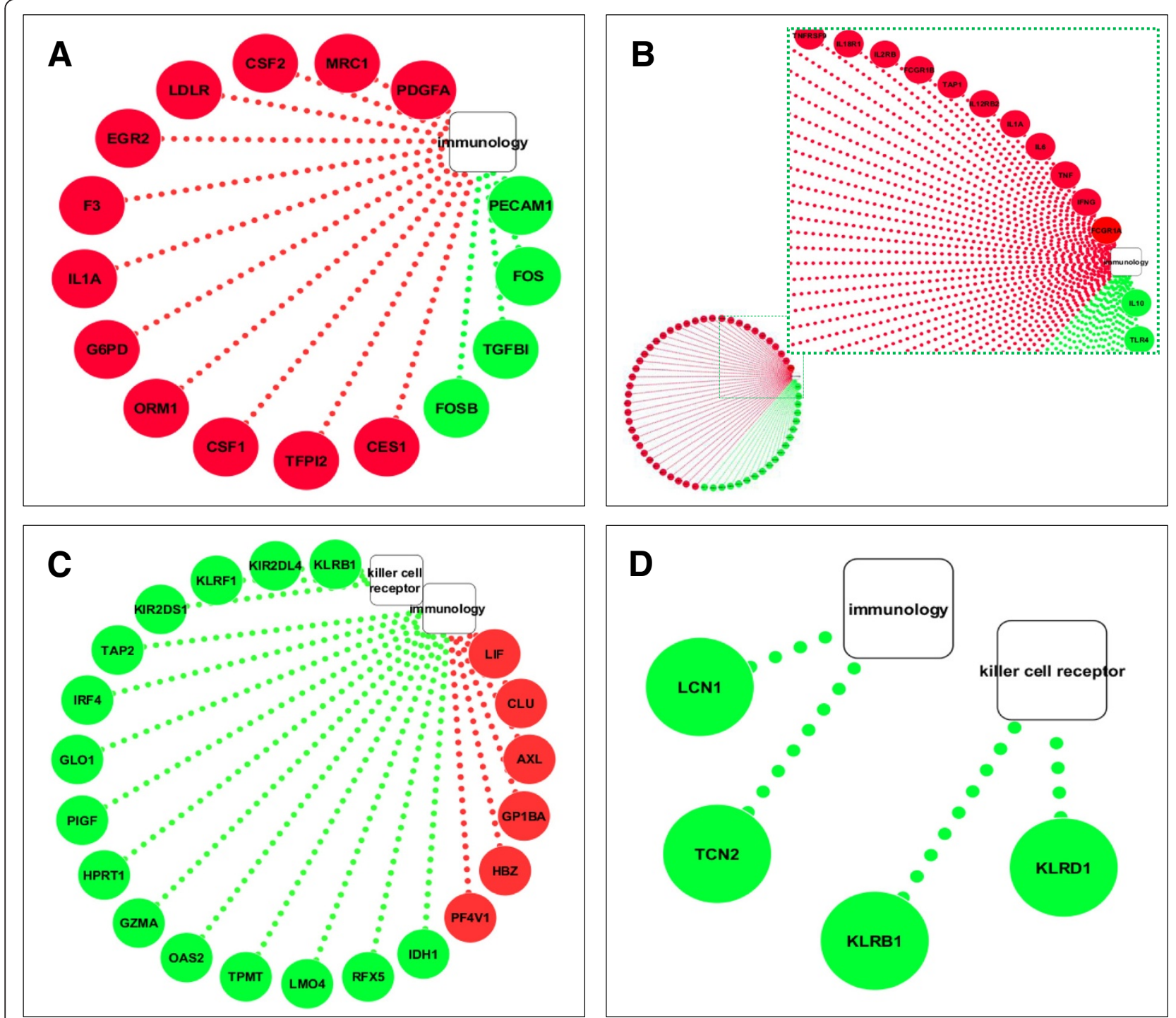

Figure 6 Unique immune signatures induced in PBMCs of BE and MML. Cytoscape analysis of immunology genes modulated by IGKV3-20 in PBMCs of BE at $24 \mathrm{~h} \mathrm{(A)}$ and $6 \mathrm{~d}$ (B). Cytoscape analysis of immunology genes and killer cell receptor genes modulated by IGKV3-20 in PBMCs of MML at $24 \mathrm{~h}(\mathrm{C})$ and $6 \mathrm{~d}(\mathrm{D})$.

In this respect, the pronounced pro-inflammatory pattern induced by IGKV3-20 in PBMCs of BE strongly resembles the expression profile elicited by the same antigen in a cohort of $\mathrm{HCV}$-negative healthy control subjects, as indicated in Figures 3 and 5.

On the contrary, a global down-regulation of immune genes such as killer cell receptor genes in PBMCs of MML may even suggest the inefficient establishment of NK cellmediated innate immune response to the candidate idiotype vaccine.

Overall, the multiparametric analysis performed on PBMCs loaded ex vivo with the IGKV3-20 candidate idiotypic vaccine shows that the identification of specific gene transcriptional patterns to confirm differences in the immune response evaluated by means of different parameters (e.g., cytokine profile) is feasible.

Indeed, subjects BE and MML are clearly different regardless the parameters used to analyze the ex vivo effect of the IGKV3-20 on their PBMCs, suggesting a possible marked diversity of their responsiveness to such an antigen if administered in vivo.

In conclusion, the present study represents a proof of concept and larger cohort studies will be needed to validate the results. Nevertheless, our results strongly suggest that our ex vivo screening platform is potentially useful to identify "proficient" prediction markers of individual responsiveness 


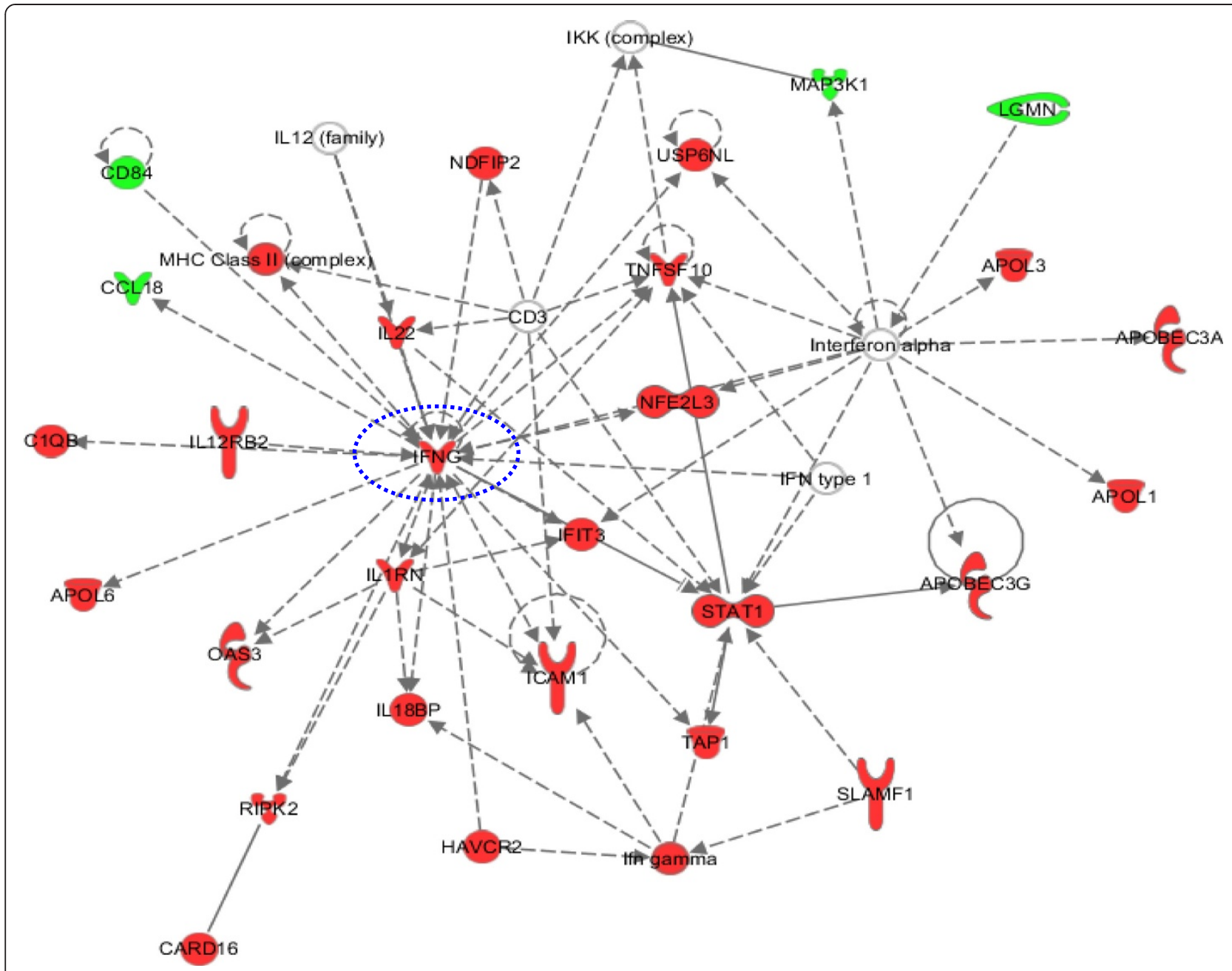

Figure 7 Ingenuity pathways analysis. IFNy signaling pathway uniquely activated in PBMCs of subject BE after 6 days stimulation with IGKV3-20.

to a specific antigen, or classes of antigens (e.g., peptides, proteins, DNA), as well as to guide optimization of vaccine design.

Moreover, systems biology approaches not only allows the scrutiny of a global picture of vaccine-induced immune effect but can be also used to uncover new correlates of vaccine efficacy [34].

\section{Competing interests}

The authors declare that they have no competing interests.

\section{Authors' contributions}

AP conducted the statistical analyses and wrote the paper; MT and MLT contributed to the statistical analyses; FMB and LB conceived and designed the study. All authors read and approved the final manuscript.

\section{Acknowledgements}

The study was funded by Italian Ministry of Research through the project "Alleanza Contro il Cancro" (Contract No. ACC 4). A.P. was Ph.D. student at University of Udine "Biomedical Science and Biotechnology" and recipient of fellowship granted through the project.

Received: 22 November 2013 Accepted: 13 January 2014

Published: 15 January 2014

\section{References}

1. Moradpour D, Blum HE: Pathogenesis of hepatocellular carcinoma. Eur J Gastroenterol Hepatol 2005, 17:477-483.

2. Zuckerman E, Zuckerman T, Levine AM, Douer D, Gutekunst K, Mizokami M, Qian DG, Velankar M, Nathwani BN, Fong TL: Hepatitis C virus infection in patients with B-cell non-Hodgkin lymphoma. Ann Intern Med 1997, 127:423-428.

3. Ferri C, Caracciolo F, Zignego AL, La CL, Monti M, Longombardo G, Lombardini F, Greco F, Capochiani E, Mazzoni A: Hepatitis C virus infection in patients with non-Hodgkin's lymphoma. Br J Haematol 1994, 88:392-394.

4. Ferri C, Longombardo G, La CL, Greco F, Lombardini F, Cecchetti R, Cagianelli MA, Marchi S, Monti M, Zignego AL: Hepatitis C virus chronic infection as a common cause of mixed cryoglobulinaemia and autoimmune liver disease. J Intern Med 1994, 236:31-36.

5. De Re V, Caggiari L, Simula MP, De VS, Sansonno D, Dolcetti R: B-cell lymphomas associated with HCV infection. Gastroenterology 2007, 132:1205-1207.

6. Hollander N: Current vaccination strategies for the treatment of B-cell lymphoma and multiple myeloma. Crit Rev Immunol 2009, 29:399-418.

7. Rosenberg SA: Raising the bar: the curative potential of human cancer immunotherapy. Sci Trans/ Med 2012, 4:127ps8.

8. Martorelli D, Guidoboni M, De RV, Muraro E, Turrini R, Merlo A, Pasini E, Caggiari L, Romagnoli L, Spina M, Mortarini R, Gasparotto D, Mazzucato M, Carbone A, Rosato A, Anichini A, Dolcetti R: IGKV3 proteins as candidate "off-the-shelf" vaccines for kappa-light chain-restricted B-cell nonHodgkin lymphomas. Clin Cancer Res 2012, 18:4080-4091. 
9. Buonaguro L, Petrizzo A, Tornesello M, Napolitano M, Martorelli D, Castello G, Beneduce G, De RA, Perrella O, Romagnoli L, Sousa V, De RV, Dolcetti R, Buonaguro FM: Immune signatures in human PBMCs of idiotypic vaccine for HCV-related lymphoproliferative disorders. J Trans/ Med 2010, 8:18.

10. Petrizzo A, Tornesello ML, Napolitano M, D'Alessio G, Salomone MA, Dolcetti R, De RV, Wang E, Marincola FM, Buonaguro FM, Buonaguro L: Multiparametric analyses of human PBMCs loaded ex vivo with a candidate idiotype vaccine for HCV-related lymphoproliferative disorders. PLoS One 2012, 7:e44870.

11. Aricò E, Wang E, Tornesello ML, Tagliamonte M, Lewis GK, Marincola FM, Buonaguro FM, Buonaguro L: Immature monocyte derived dendritic cells gene expression profile in response to virus-like particles stimulation. J Transl Med 2005, 3:45.

12. Buonaguro L, Monaco A, Arico E, Wang E, Tornesello ML, Lewis GK, Marincola FM, Buonaguro FM: Gene expression profile of peripheral blood mononuclear cells in response to HIV-VLPs stimulation. BMC Bioinforma 2008, 9(2):S5.

13. Buonaguro L, Tornesello ML, Gallo RC, Marincola FM, Lewis GK, Buonaguro FM: Th2 polarization in peripheral blood mononuclear cells from human immunodeficiency virus (HIV)-infected subjects, as activated by HIV virus-like particles. J Virol 2009, 83:304-313.

14. Querec TD, Akondy RS, Lee EK, Cao W, Nakaya HI, Teuwen D, Pirani A, Gernert K, Deng J, Marzolf B, Kennedy K, Wu H, Bennouna S, Oluoch H, Miller J, Vencio RZ, Mulligan M, Aderem A, Ahmed R, Pulendran B: Systems biology approach predicts immunogenicity of the yellow fever vaccine in humans. Nat Immunol 2009, 10:116-125.

15. Gaucher D, Therrien R, Kettaf N, Angermann BR, Boucher G, Filali-Mouhim A, Moser JM, Mehta RS, Drake DR III, Castro E, Akondy R, Rinfret A, Yassine-Diab B, Said EA, Chouikh Y, Cameron MJ, Clum R, Kelvin D, Somogyi R, Greller LD, Balderas RS, Wilkinson P, Pantaleo G, Tartaglia J, Haddad EK, Sekaly RP: Yellow fever vaccine induces integrated multilineage and polyfunctional immune responses. J Exp Med 2008, 205:3119-3131.

16. Eisen MB, Spellman PT, Brown PO, Botstein D: Cluster analysis and display of genome-wide expression patterns. Proc Natl Acad Sci U S A 1998, 95:14863-14868.

17. Ross DT, Scherf U, Eisen MB, Perou CM, Rees C, Spellman P, lyer $V$, Jeffrey SS, de RM V, Waltham M, Pergamenschikov A, Lee JC, Lashkari D, Shalon D, Myers TG, Weinstein JN, Botstein D, Brown PO: Systematic variation in gene expression patterns in human cancer cell lines. Nat Genet 2000, 24:227-235.

18. Milner CM, Higman VA, Day AJ: TSG-6: a pluripotent inflammatory mediator? Biochem Soc Trans 2006, 34:446-450.

19. Ha H, Han D, Choi Y: TRAF-mediated TNFR-family signaling. Curr Protoc Immunol 2009, 11:Unit11.

20. Heckmann BL, Zhang X, Xie X, Liu J: The G0/G1 switch gene 2 (G0S2): regulating metabolism and beyond. Biochim Biophys Acta 1831, 2013:276-281.

21. Worby CA, Dixon JE: Sorting out the cellular functions of sorting nexins. Nat Rev Mol Cell Biol 2002, 3:919-931.

22. Jansen PA, Kamsteeg M, Rodijk-Olthuis D, van Vlijmen-Willems IM, de Jongh GJ, Bergers M, Tjabringa GS, Zeeuwen PL, Schalkwijk J: Expression of the vanin gene family in normal and inflamed human skin: induction by proinflammatory cytokines. J Invest Dermatol 2009, 129:2167-2174.

23. Fairfax BP, Davenport EE, Makino S, Hill AV, Vannberg FO, Knight JC: A common haplotype of the TNF receptor 2 gene modulates endotoxin tolerance. J Immunol 2011, 186:3058-3065.

24. Graham LM, Gupta V, Schafer G, Reid DM, Kimberg M, Dennehy KM, Hornsell WG, Guler R, Campanero-Rhodes MA, Palma AS, Feizi T, Kim SK, Sobieszczuk P, Willment JA, Brown GD: The C-type lectin receptor CLECSF8 (CLEC4D) is expressed by myeloid cells and triggers cellular activation through Syk kinase. J Biol Chem 2012, 287:25964-25974.

25. Arce I, Martinez-Munoz L, Roda-Navarro P, Fernandez-Ruiz E: The human Ctype lectin CLECSF8 is a novel monocyte/macrophage endocytic receptor. Eur J Immunol 2004, 34:210-220.

26. Amarnath S, Mangus CW, Wang JC, Wei F, He A, Kapoor V, Foley JE, Massey PR, Felizardo TC, Riley JL, Levine BL, June CH, Medin JA, Fowler DH: The PDL1-PD1 axis converts human TH1 cells into regulatory T cells. Sci Trans/ Med 2011, 3:111ra120.

27. Borges L, Hsu ML, Fanger N, Kubin M, Cosman D: A family of human lymphoid and myeloid Ig-like receptors, some of which bind to $\mathrm{MHC}$ class I molecules. J Immunol 1997, 159:5192-5196.
28. Lagaudriere-Gesbert C, Lebel-Binay S, Wiertz E, Ploegh HL, Fradelizi D, Conjeaud $\mathrm{H}$ : The tetraspanin protein CD82 associates with both free HLA class I heavy chain and heterodimeric beta 2-microglobulin complexes. J Immunol 1997, 158:2790-2797.

29. Mata-Espinosa DA, Hernandez-Pando R: Gamma interferon: basics aspects, clinic significance and terapeutic uses. Rev Invest Clin 2008, 60:421-431.

30. Rajalingam R: Overview of the killer cell immunoglobulin-like receptor system. Methods Mol Biol 2012, 882:391-414.

31. Buonaguro L, Wang E, Tornesello ML, Buonaguro FM, Marincola FM: Systems biology applied to vaccine and immunotherapy development. BMC Syst Biol 2011, 5:146.

32. Berzofsky JA: Improving immunotherapy: revisiting the immunologist's little secret. Sci Trans/ Med 2012, 4:120fs4.

33. Ali OA, Emerich D, Dranoff G, Mooney DJ: In situ regulation of DC subsets and T cells mediates tumor regression in mice. Sci Transl Med 2009, 1:8ra19.

34. Rappuoli R, Medaglini D: ADITEC: joining forces for next-generation vaccines. Sci Transl Med 2012, 4:128cm4.

doi:10.1186/1479-5876-12-11

Cite this article as: Petrizzo et al.: Prediction of individual immune responsiveness to a candidate vaccine by a systems vaccinology approach. Journal of Translational Medicine 2014 12:11.

\section{Submit your next manuscript to BioMed Central and take full advantage of:}

- Convenient online submission

- Thorough peer review

- No space constraints or color figure charges

- Immediate publication on acceptance

- Inclusion in PubMed, CAS, Scopus and Google Scholar

- Research which is freely available for redistribution

Submit your manuscript at www.biomedcentral.com/submit
C) Biomed Central 